\title{
Farklı Dayanıkııık Antrenmanlarında Oluşan Sıvı Kaybının İncelenmesi
}

\section{Mehmet Akif BABUR ${ }^{1}$ D, Hakan YARAR ${ }^{1^{*}}$, Hasan IȘLEK $^{1}$ H, $^{\mathbb{D}}$, Volkan ŞUBATLIOĞLU' ${ }^{1}$, Gülnur TEMELLI' ${ }^{2}{ }^{\circledR}$}

\author{
${ }^{1}$ Bolu Abant İzzet Baysal Üniversitesi, Spor Bilimleri fakültesi.
} ${ }^{2}$ Bolu Abant İzzet Baysal Üniversitesi, Sağlık Bilimleri Fakültes.

Orijinal Makale

Gönderi Tarihi: 03.11.2020
Kabul Tarihi: 29.11.2020
DOI:10.25307/jssr.820196

Online Yayın Tarihi: 31.12 .2020

\section{Öz}

Yapılan bu çalışmanın amacı iki farklı ortamda yapılan (karada ve suda) dayanıklılık antrenmanının vücut sıvı miktarı üzerine etkilerinin incelenmesidir. Bu çalışmaya yüzme eğitimi almış $[(\bar{X}+s s)$ yaş: $20,06 \pm 1,91$ yıl; boy: $178,06 \pm 7,84 \mathrm{~cm}$; vücut

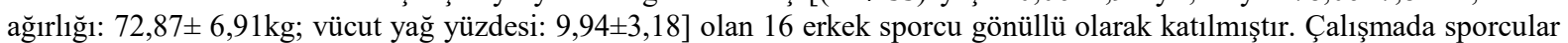
rastgele örneklem seçim yöntemi ile 2 eşit gruba ayrılmış ( 8 kara antrenmanı gurubu, 8 su içi egzersiz grubu) ve 15 dakikalık 1sınma ile birlikte toplam 2 saat dayanıklılık antrenmanı uygulamıştır. Çalışmada ilk uygulamalar tamamlandıktan sonra 24 saat ara verilmiştir. Sonrasında kara antrenman grubu su içi egzersiz, su içi egzersiz grubu ise kara antrenmanı uygulamıştır. Bu esnada iki saatlik dayanıklılık antrenmanı öncesi ve hemen sonrası vücut kompozisyonu ölçümleri (vücut ağırlı̆̆ı, vücut sıvı miktarı, kas kütlesi vücut yağ yüzdesi), idrar yoğunluğu ve vücut sıcaklığı ölçümleri yapılmıştır. İstatistiksel analizlerde eşleştirilmiş örneklerde t-testi kullanılmıştır. Yapılan istatistiksel analiz sonucunda vücut ağırlığı, vücut sıvı miktarı, kas kütlesi, vücut yağ yüzdesi ve vücut sıcaklığı değerlerinde anlamlı fark olduğu ( $<<0,05)$, idrar yoğunluğunda ise istatistiksel olarak anlamlı bir fark olmadığ $(p>0,05)$ belirlenmiştir. Sonuç olarak her iki ortamda da yapılan dayanıklılık egzersizlerinde vücut sıvı miktarı, kas oranı ve vücut sıcaklığı değerlerinde istatistiksel olarak önemli değişiklikler olduğu tespit edilmiştir. Anahtar kelimeler: Dayanıklılık, Dehidrasyon, İdrar yoğunluğu, Vücut kompozisyonu.

\section{The Investigation of Fluid Loss in Different Endurance Training}

\begin{abstract}
The aim of this study is to examine the effects of endurance training in two different environments (land and water) on the amount of body fluid. 16 male athletes who have taken swimming training voluntarily participated in this study [(mean \pm SD) age: $20.06 \pm 1.91$ years; height: $178.06 \pm 7.84 \mathrm{~cm}$; body weight: $72.87 \pm 6.91 \mathrm{~kg}$; body fat percentage: $9.94 \pm 3.18]$. In the study, the athletes were randomly divided into 2 equal groups ( 8 land training groups, 8 underwater exercise groups) and a total of 2 hours of endurance training was applied with 15 minutes of warm-up. In the study, after the first applications were completed, a break was given for 24 hours, after which the land training group applied in-water exercise and the in-water exercise group applied land training. In the meantime, body composition measurements (body weight, body fluid amount, muscle mass, body fat percentage), urine density and body temperature were measured before and just after the two-hour endurance training. For the statistical analysis paired sample t-test was used. As a result of the statistical analysis, it was determined that there was a significant difference in body weight, body fluid amount, muscle mass, body fat percentage and body temperature $(p<0,05)$, but there was no statistically significant difference in urine density ( $>>0,05)$. As a result, it was determined that there are statistically significant changes in body fluid amount, muscle ratio and body temperature values in endurance exercises performed in both environments.
\end{abstract}

Keywords: Endurance, Dehydration, Urine specific gravity, Body composition.

\footnotetext{
* Sorumlu Yazar: Hakan YARAR, Eposta: hakan.yarar@ibu.edu.tr
} 


\section{GíRiş}

Dayanıklılık, uzun süreli egzersizlerde organizmanın yorgunluğa karşı vermiş olduğu mücadele yeteneği olarak tanımlanmaktadır (Sevim, 2007) ve kesintisiz olarak süresi 60 saniyenin üzerinde olan spor branşlarında oldukça önemli bir motorik özelliktir (Bompa, 2001). Sporcuların dayanıklılık performansını etkileyen birçok faktör bulunmaktadır. Bunlar: motorik faktörler; kuvvet, sürat, çeviklik, reaksiyon, koordinasyon, denge, fizyolojik faktörler; maksimal aerobik kapasite, kas fibril tipleri, laktat eşiği ve egzersiz ekonomisine bağlıdır. Bunların dışında sporcunun sağlığı, beslenmesi, dinlenmesi, psikolojik durumu ve hidrasyon düzeyi de dayanıklılık performansını etkileyen faktörler arasında yer almaktadır (Hoffman, 2002). Tüm performans bileşenleri belli ölçüde vücut kompozisyonuna bağlıdır. Vücut kompozisyonu kaslar, kemikler, yağlar, çeşitli organik maddeler ve hücre dışı sıvılarından oluşmaktadır. Egzersizin başlamasıyla birlikte vücut kompozisyonunu oluşturan bu ögelerde değişiklikler meydana gelmektedir. Özellikle vücut sıvı miktarında terlemeye bağlı olarak azalma oluşur (Çırak ve Çakıroğlu Funda, 2017).

Sıv1 tüketimi insan vücudu için oldukça önemlidir. Besinlerin tüketimi, tüketilen besinlerin sindirimi, emilimi, hücrelere taşınması, metabolizmaları sonucu oluşan atıkların akciğer ve böbreklere taşınıp dışarı atılmaları, eklemlerin kayganlığının sağlanması, elektrolitlerin taşınması (Baysal, 1997; Singh, 2003; Sevim, 2007; Çırak ve Çakıroğlu Funda, 2017), hücresel biyokimyasal tepkimelerin sürekliliğinin sağlaması ve vücut sıcaklığı dengesi gibi birçok önemli göreve sahiptir (Armstrong, 2005). Günlük alınması gereken sıvı miktarı iklim ve çalışma koşulları, hastalıklar, diyet ve vücudun hormon dengesi gibi etkenlere bağlı olarak değişir (Baysal, 1997). Vücut, harcadığı kadar sıvı alamazsa dehidratasyon süreci başlamış olur. Sporcular uzun süreli egzersiz esnasında terlemeye bağlı olarak vücutlarından su kaybetmektedirler (Gökdemir, 2000). Su eksikliğinde organizma işlevsel olarak zarar görür ve verimi düşer (Konopka, 2000). Egzersiz esnasında vücut sıvı dengesi, dolaşım ve 1s1 düzenleme fonksiyonları açısından oldukça önemlidir (Wilmore ve Costill, 2004). Yeterli sıvı tüketimi durumunda, egzersiz başlangıcında vücutta, sıvı miktarı denge halindedir. Antrenman esnasında ise yoğun terlemeye bağlı olarak bu denge bozulur (Wilmore ve Costill, 2004; Shirreffs, 2009).

Müsabaka ve antrenman öncesinde ve sirasında tüketilen s1v1, sporcunun performansını ve sağlığını doğrudan etkileyeceğinden büyük önem taşımaktadır (Natalie ve diğerleri 2014). Hem karada hem de suda yapılan dayanıklılık egzersizlerinde düzenli aralıklarla sıv1 tüketilmesi oldukça önemdir. Ancak yüzme gibi su içerisinde yapılan aktivitelerde sıv1 tüketimine pek dikkat edilmediği ve sıvı alımının göz ardı edildiği düşünülmektedir (Ersoy, Er ve Özgürtaş, 2013; Yapıcı, Kavruk ve Çelik, 2017). Bu bakımdan yapılan bu çalışmanın amacı iki farklı ortamda yapılan (karada ve suda) dayanıklılık antrenmanının vücut sıvı miktarı üzerine etkilerinin incelenmesidir.

\section{METOT}

\section{Araştırma Grubu}

Yapılan araştırmaya, Bolu Abant İzzet Baysal Üniversitesi Spor Bilimleri Fakültesinde öğrenim gören, yüzme eğitimi almış $[(\mathrm{X} \pm \mathrm{S})$ yaş: $20,06 \pm 1,91$ y1l; boy: $178,06 \pm 7,84 \mathrm{~cm}$; vücut

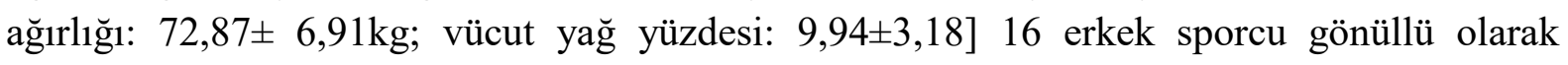
katılmıştır.

\section{Çalışma Deseni}

Çalışma başlamadan iki hafta önce sporcularla toplantı yapılarak; araştırmanın amacı, süresi, araştırmada uygulanacak testler, çalışma esnasında oluşabilecek olası riskler ve çalışmadan 
elde edilecek yararlar hakkında detaylı bilgi verilmiştir. Çalışmada antropometrik ölçümler ve vücut kompozisyonu ölçümleri Bolu Abant İzzet Baysal Üniversitesi, Spor Bilimleri Fakültesi fizyoloji laboratuvarında gerçekleştirilmiştir. Karada ve suda yapılan uygulamalar ise Yüzme Havuzu ve Fitness Merkezinde gerçekleştirilmiştir. Sporcuların gönüllü olarak katılımları sağlanmış ve gönüllü olduklarını belirten formu okuyarak imzalamaları istenmiştir. Ana ölçümlere başlandığında katılımcılar rastgele örneklem seçim yöntemiyle iki eşit gruba ayrılmış ve bir gruba toplam 2 saat süren kara antrenmanı, diğer gruba ise 2 saat yüzme antrenmanı yaptırılmıştır. Çalışmada ilk uygulamalar tamamlandıktan sonra 24 saat ara verilmiş ve kara antrenman uygulaması yapanlara yüzme antrenmanı, yüzme antrenmanı yapanlara ise kara antrenman uygulaması yaptırılmıştır. Uygulamalar esnasında 2 saat boyunca sporcular sıvı tüketimi yapmamıştır. Bu esnada iki saatlik kara ve yüzme antrenmanı öncesi ve hemen sonrası vücut kompozisyonu ölçümleri (vücut ağırlığı, vücut sıvı miktarı, kas kütlesi vücut yă̆ yüzdesi), idrar yoğunluğu ve vücut sıcaklığı ölçümleri yapılmıştır. Detaylı bilgi Tablo 1'de verilmiştir.

Tablo 1. Çalışma Deseni

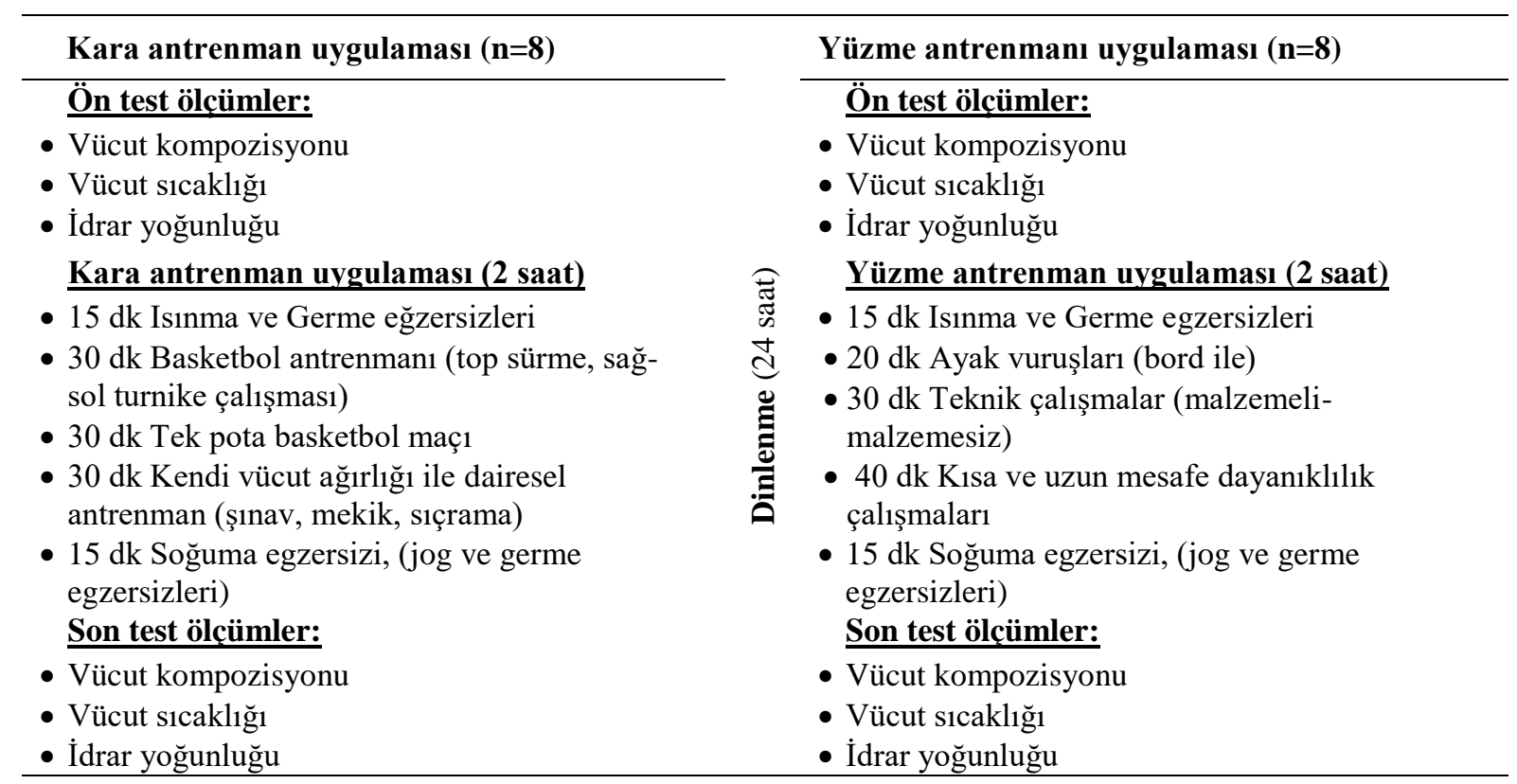

\section{Veri Toplama Araçları}

Kilo ve Boy Ölçümleri: Sporcuların vücut ağırlığı ve boy uzunluğu ölçümleri Seca marka tartiyla (Seca 700, Medical Scales and Measuring Systems, Hamburg-GERMANY) üzerlerinde yalnız şort ve tişört varken çıplak ayakla ölçülmüştür.

Vücut Kompozisyonu: Vücut kompozisyonu (Vücut yağ oran1, kas oran1, sıv1 oran1) ölçümü Tanita marka (BC-418 MA marka) 100 gr hassaslığındaki vücut yağ analizöründe gerçekleştirilmiştir. 
İdrar yoğunluğu ölçümleri: Katılımcıların idrar yoğunluğu düzeylerinin belirlenmesi için ELine Hand Held Refractometer (B+S Code 44-891) marka refraktometre kullanılmıştır. İdrar örnekleri steril kaplarda alınmış ve 2 saat içinde analizleri yapılmıştır. Ölçümler antrenman öncesi ve antrenman sonrası iki defa alınmış ve aynı kişi tarafından analiz edilmiştir.

Vücut sıcaklığı ölçümü: Sporcuların vücut sıcaklığı ölçümü; kulak zarı ve etrafındaki 1sıyı ölçen hazır ticari (Braun TermoScan IRT 4520) timpanik termometre kullanılarak yapılmıştır. Kulaktan 1sı ölçümünde termometre dış kulağın 1/3'lük kısmına yerleştirilerek sinyal sesi gelene kadar beklenilmiş ve ölçüm kaydedilmiştir. Her ölçüm için kişiye özel tek kullanımlık başlık ile ölçüm yapılmıştır.

Araştırma Etiği: Bu çalışma, Bolu Abant İzzet Baysal Üniversitesi Klinik Araştırmalar Etik Kurulu tarafindan etik olarak uygun bulunmuştur (Tarih: 21.01.2020, Karar no: 2019/316).

\section{Verilerin Analizi}

Elde edilen veriler SPSS 20.0 paket programı kullanılarak aritmetik ortalamaları, standart sapmaları, minimum maksimum değerleri belirlenerek, uygulamalar arası karşılaştırmalar için eşleştirilmiş örneklemde $\mathrm{t}$ testi (Paired sample T-testi) kullanılmıştır. Anlamlılık değeri tüm istatistiksel analizlerde $\mathrm{p}<0,05$ olarak kabul edilmiştir.

\section{BULGULAR}

Tablo 2. İdrar yoğunluğu değerlerinin karşılaştırılması (n:16)

\begin{tabular}{|c|c|c|c|c|c|}
\hline & Değişkenler & Ölçümler & $(\mathrm{X} \pm \mathrm{S})$ & $\mathbf{t}$ & $\mathbf{p}$ \\
\hline \multirow{8}{*}{ 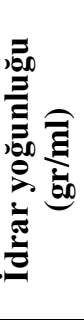 } & & Ön test & $1022,37 \pm 3,16$ & \multirow{2}{*}{0,48} & \multirow{2}{*}{0,63} \\
\hline & Havuz Antrenmanı Grubu & Son test & $1021,81 \pm 5,02$ & & \\
\hline & Kara Antrenman Grubu & Ön test & $1020,31 \pm 5,18$ & \multirow{2}{*}{$-0,34$} & \multirow{2}{*}{0,73} \\
\hline & Kara Antrenmani Grubu & Son test & $1021,00 \pm 8,40$ & & \\
\hline & Ön test deŏerlerinin karclasturlmas & Ön test & $1022,37 \pm 3,16$ & \multirow{2}{*}{1,53} & \multirow{2}{*}{0,14} \\
\hline & Un test uegeriermm karşuaşummast & Ön test & $1020,31 \pm 5,18$ & & \\
\hline & Son test deŏerlerinin karsulasturulmas & Son test & $1021,81 \pm 5,02$ & \multirow{2}{*}{0,31} & \multirow{2}{*}{0,75} \\
\hline & 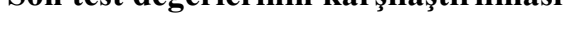 & Son test & $1021,00 \pm 8,40$ & & \\
\hline
\end{tabular}

Katılmcıların idrar yoğunlugu değerleri incelendiğinde havuzda ve karada yapılan antrenmanlarda idrar yoğunlugu bakımından tüm değerlerde istatistiksel olarak anlamlı fark olmadığı ( $\mathrm{p}>0,05)$ görülmektedir (Tablo 2).

Tablo 3. Vücut sıcaklığı değerlerinin karșılaștırılması

\begin{tabular}{|c|c|c|c|c|c|}
\hline & Değişkenler & Ölçümler & $(\mathrm{X} \pm \mathrm{S})$ & $\mathbf{t}$ & $\mathbf{p}$ \\
\hline \multirow{8}{*}{ 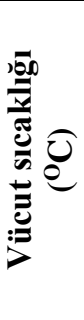 } & Havuz Antrenmani Grubu & Ön test & $36,81 \pm 3,16$ & \multirow{2}{*}{4,27} & \multirow{2}{*}{$\mathbf{0 , 0 0 *}$} \\
\hline & Gavuz Amtremiant Gruou & Son test & $35,72 \pm 5,02$ & & \\
\hline & \multirow{2}{*}{ Kara Antrenmanı Grubu } & Ön test & $36,11 \pm 5,18$ & \multirow{2}{*}{$-3,60$} & \multirow{2}{*}{$\mathbf{0 , 0 0 *}$} \\
\hline & & Son test & $36,60 \pm 8,40$ & & \\
\hline & \multirow{2}{*}{ Ön test değerlerinin karşılaştırılması } & Ön test & $36,81 \pm 3,16$ & \multirow{2}{*}{4,70} & \multirow{2}{*}{$\mathbf{0 , 0 0 *}$} \\
\hline & & Ön test & $36,11 \pm 5,18$ & & \\
\hline & \multirow{2}{*}{ Son test değerlerinin karşılaştırılması } & Son test & $35,72 \pm 5,02$ & \multirow{2}{*}{$-3,79$} & \multirow{2}{*}{$\mathbf{0 , 0 0 *}$} \\
\hline & & Son test & $36,60 \pm 8,40$ & & \\
\hline
\end{tabular}

*p<0,05

Vücut sıcaklığı değerleri incelendiğinde havuzda ve karada yapılan antrenmanlarda vücut sıcaklığı ön test son test değerleri bakımından istatistiksel olarak anlamlı fark olduğu $(\mathrm{p}<0,05)$ 
görülmektedir. Ayrıca her iki grubun öntest $(\mathrm{p}<0,00)$ ve sontest $(\mathrm{p}<0,00)$ değerleri karşılaştırmasında da istatistiksel olarak anlamlı fark oldugu görülmektedir (Tablo 3). Havuz antrenman grubu vücut sıcaklığı değerlerinde düşüş, kara antrenman grubunda ise vücut sıcaklığı değerlerinde artış olduğu belirlenmiştir.

Tablo 4. Vücut ağırlığı değerlerinin karşılaştırılması

\begin{tabular}{|c|c|c|c|c|c|}
\hline & Değişkenler & Ölçümler & $(\mathrm{X} \pm \mathrm{S})$ & $\mathbf{t}$ & $\mathbf{p}$ \\
\hline \multirow{8}{*}{ 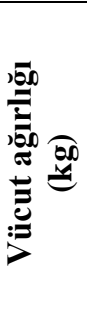 } & Havuz Antrenmanı Grubu & Ön test & $72,83 \pm 5,65$ & \multirow{2}{*}{2,97} & \multirow{2}{*}{$\mathbf{0 , 0 1 *}$} \\
\hline & & Son test & $72,60 \pm 6,74$ & & \\
\hline & Kara Antrenmanı Grubu & Ön test & $72,96 \pm 5,65$ & \multirow{2}{*}{6,10} & \multirow{2}{*}{$\mathbf{0 , 0 0 *}$} \\
\hline & & Son test & $72,35 \pm 6,74$ & & \\
\hline & \multirow{2}{*}{ Ön test değerlerinin karşılaştırılması } & Ön test & $72,83 \pm 5,65$ & \multirow{2}{*}{,- 68} & \multirow{2}{*}{0,50} \\
\hline & & Ön test & $72,96 \pm 5,65$ & & \\
\hline & \multirow{2}{*}{ Son test değerlerinin karşılaştırılması } & Son test & $72,60 \pm 6,74$ & \multirow{2}{*}{1,50} & \multirow{2}{*}{0,15} \\
\hline & & Son test & $72,35 \pm 6,74$ & & \\
\hline
\end{tabular}

Vücut ağırlığı değerleri incelendiğinde havuzda ve karada yapılan antrenmanlarda vücut ağırlığı ön test son test değerleri bakımından istatistiksel olarak anlamlı fark olduğu $(\mathrm{p}<0,05)$ görülmektedir. Ayrıca öntest değerlerinin karşılaştırılması $(\mathrm{p}=0,50)$ ve sontest degerlerinin karşılaştırılmasında $(\mathrm{p}=0,15)$ ise anlamlı fark olmadı̆̆ grupta da vücut ağırlığı değerlerinde düşüş olduğu belirlenmiştir.

Tablo 5. Vücut sıvı miktarı değerlerinin karşılaştırılması

\begin{tabular}{|c|c|c|c|c|c|}
\hline & Değişkenler & Ölçüimler & $(\mathrm{X} \pm \mathrm{S})$ & $\mathbf{t}$ & $\mathbf{p}$ \\
\hline \multirow{5}{*}{ 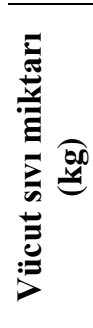 } & Havuz Antrenmanı Grubu & $\begin{array}{l}\text { Ön test } \\
\text { Son test }\end{array}$ & $\begin{array}{l}47,92 \pm 6,73 \\
46,61 \pm 4,29\end{array}$ & 7,48 & $\mathbf{0 , 0 0 *}$ \\
\hline & Kara Antrenmanı Grubu & Ön test & $48,23 \pm 4,34$ & 3.48 & $0.00 *$ \\
\hline & Кат а Анा & $\begin{array}{l}\text { Son test } \\
\ddot{0} \text {. }\end{array}$ & $47,43 \pm 4,19$ & & \\
\hline & Ön test değerlerinin karşılaştırılması & $\begin{array}{l}\text { On test } \\
\text { Ön test }\end{array}$ & 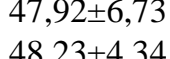 & $-1,18$ & 0,25 \\
\hline & Son test değerlerinin karşılaştırılması & $\begin{array}{l}\text { Son test } \\
\text { Son test }\end{array}$ & $\begin{array}{l}46,61 \pm 4,29 \\
47,43 \pm 4,19\end{array}$ & $-3,12$ & $0,00 *$ \\
\hline
\end{tabular}

Vücut sıvı miktarı değerleri incelendiğinde havuzda ve karada yapılan antrenmanlarda vücut sıv1 miktarı ön test son test değerleri bakımından istatistiksel olarak anlamlı fark olduğu $(\mathrm{p}<0,05)$ görülmektedir (Tablo 5). Aynı şekilde sontest değerleri karşılaştırmasında da anlamlı fark olduğu $(\mathrm{p}<0,05)$ belirlenmiştir. Yanlızca öntest değerlerinin karşılaştırmasında ise fark olmadığ $1(p<0,25)$ tespit edilmiştir. Her iki grupta da vücut sıvı miktarı değerlerinde düşüş olduğu belirlenmiştir.

Tablo 6. Kas oranı değerlerinin karşılaştırılması

\begin{tabular}{|c|c|c|c|c|c|}
\hline & Değişkenler & Ölçümler & $(\mathrm{X} \pm \mathrm{S})$ & $\mathbf{t}$ & $\mathbf{p}$ \\
\hline \multirow{8}{*}{ 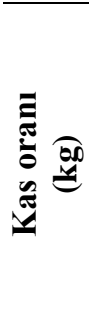 } & & Ön test & $62,46 \pm 5,63$ & \multirow{2}{*}{4,60} & \multirow{2}{*}{$\mathbf{0 , 0 0 *}$} \\
\hline & Havuz Antrenmanı Grubu & Son test & $61,05 \pm 5,65$ & & \\
\hline & Kare Antrenman Grubu & Ön test & $62,90 \pm 5,76$ & \multirow{2}{*}{3,618} & \multirow{2}{*}{$\mathbf{0 , 0 0 *}$} \\
\hline & Kara Antrenmani Gruou & Son test & $61,78 \pm 5,48$ & & \\
\hline & \multirow{2}{*}{ Ön test değerlerinin karşılaştırılması } & Ön test & $62,46 \pm 5,63$ & \multirow{2}{*}{$-1,322$} & \multirow{2}{*}{0,20} \\
\hline & & Ön test & $62,90 \pm 5,76$ & & \\
\hline & \multirow{2}{*}{ Son test değerlerinin karşılaştırılması } & Son test & $61,05 \pm 5,65$ & \multirow{2}{*}{$-2,117$} & \multirow{2}{*}{0,05} \\
\hline & & Son test & $61,78 \pm 5,48$ & & \\
\hline
\end{tabular}

*p<0,05

Katılmcıların kas oranı incelendiğinde havuzda ve karada yapılan antrenmanlarda kas oranı ön test son test değerleri bakımından istatistiksel olarak anlamlı fark olduğu $(p<0,05)$ 
görülmektedir. Ancak havuz ve kara antrenman grubu öntest değerleri karışıtırılmasında istatistiksel olarak anlamlı fark olmadığı tespit edilmiştir $(p=0.20)$. Aynı şekilde sontest değerlerinde de istatistiksel olarak fark olmadığ 1 belirlenmiştir $(\mathrm{p}=0,05)$ (Tablo 6).

Tablo 7. Yağ oranı değerlerinin karşılaştırılması

\begin{tabular}{|c|c|c|c|c|c|}
\hline & Değişkenler & Ölçümler & $(\mathbf{X} \pm \mathbf{S})$ & $\mathbf{t}$ & $\mathbf{p}$ \\
\hline \multirow{8}{*}{ 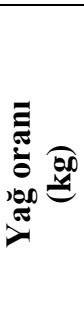 } & \multirow{2}{*}{ Havuz Antrenmanı Grubu } & Ön test & $7,36 \pm 92,56$ & \multirow{2}{*}{$-4,66$} & \multirow{2}{*}{$\mathbf{0 , 0 0 *}$} \\
\hline & & Son test & $8,78 \pm 92,54$ & & \\
\hline & & Ön test & $6,43 \pm 92,58$ & -576 & $000 *$ \\
\hline & Kara Antrenmanı Grubu & Son test & $8,18 \pm 92,83$ & $-5, / 0$ & $0,00 \%$ \\
\hline & \multirow{2}{*}{ Ön test değerlerinin karşılaştırılması } & Ön test & $7,36 \pm 92,56$ & \multirow{2}{*}{3,62} & \multirow{2}{*}{$\mathbf{0 , 0 0 *}$} \\
\hline & & Ön test & $6,43 \pm 92,58$ & & \\
\hline & \multirow{2}{*}{ Son test değerlerinin karşılaştırılması } & Son test & $8,78 \pm 92,54$ & \multirow{2}{*}{2,10} & \multirow{2}{*}{0,05} \\
\hline & & Son test & $8,18 \pm 92,83$ & & \\
\hline
\end{tabular}

*p<0,05

Katılmcıların yă̆ oranı incelendiğinde havuzda ve karada yapılan antrenmanlarda yağ oranı ön test son test değerleri bakımından istatistiksel olarak anlamlı fark olduğu $(\mathrm{p}<0,05)$ görülmektedir. Aynı şekilde havuz ve kara antrenman grubu öntest değerleri karşılatırıldığında istatistiksel olarak fark olduğu belirlenmiştir $(p<0,05)$. Ancak sontest değerleri arasındaki karşılaştırmada ise istatistiksel olarak anlamlı fark olmadığı tespit edilmiştir $(\mathrm{p}=0,05)$ (Tablo 7).

\section{TARTIŞMA VE SONUÇ}

Yapılan bu çalışmanın amacı, iki farklı ortamda yapılan (karada ve suda) dayanıklılık antrenmanının vücut sıvı miktarı üzerine etkilerinin incelenmesidir. Araştırmanın en önemli bulguları incelendiğinde her iki antrenman yönteminde de vücut ağırlığı, vücut sıvı miktarı ve kas kütlesinde istatistiksel olarak anlamlı düşüş $(\mathrm{p}<0,05)$; vücut sıcaklığı değerlerinde havuz uygulamasında düşüş, kara antrenman uygulamasında ise artış olduğu belirlenmiştir. İdrar yoğunluğunda istatistiksel olarak anlamlı bir fark olmadığg ( $p>0,05)$, vücut yağ yüzdesinde ise artış olduğu tespit edilmiştir.

Çalışmada idrar yoğunluğu değerleri incelendiğinde havuzda ve karada yapılan uygulamalar arasında idrar yoğunluğu bakımından istatistiksel olarak anlamlı fark olmadığ $(\mathrm{p}>0,05)$, ancak karada yapılan uygulamada idrar yoğunluğunda artış olduğu tespit edilmiştir (Tablo 2). Benzer şekilde Adams ve diğerleri, (2015); Arnaoutis ve diğerleri, (2015) ve Macaluso ve diğerlerinin (2011) yapmış oldukları çalışmalarda, yüzücülerin egzersiz öncesi ve sonrası idrar yoğunluğunu incelemiş ve istatistiksel olarak anlamlı fark olmadığını belirtmiştir. Ayrıca Dölek ve diğerleri (2014) ile Yapıcı ve diğerlerinin (2017) yapmış oldukları çalışmalarda ise su takviyeli antrenmanlarda idrar yoğunluğunda fark olmadığını, su takviyesiz antrenmanlarda ise anlamlı artış olduğunu tespit etmişlerdir. Bu bağlamda düzenli sıvı tüketiminin idrar yoğunluğu üzerinde olumlu etkisi olduğu söylenebilir.

Katılımcıların vücut sıcaklığı değerleri incelendiğinde, su içerisinde yapılan uygulamada \%2,96 oranında düşüş olduğu, karada yapılan antrenmanlarda ise vücut sıcaklığ 1 değerlerinde $\% 1,35$ artış olduğu tespit edilmiştir $(\mathrm{p}<0,05)$ (Tablo 3). Benzer şekilde Yapıcı ve diğerlerinin, (2017) yapmış oldukları çalışmada yüzücülerde eşik dayanıklılık antrenmanı (end-2) sonucunda oluşan dehidrasyonun performans üzerine etkilerini ve vücut hidrasyon düzeyini incelemiş ve vücut sıcaklığı değerlerinde su içerisinde düşüş olduğunu tespit edilmiştir. Aynı 
şekilde Dölek ve diğerleri (2014), yapmış oldukları çalışmada yüzmenin neden olduğu vücut sıvı dengesindeki değiş̧imleri incelemiş ve havuz içerisinde yapılan antrenmanlarda hem sıvı takviyeli hem sıvı takviyesiz uygulamalarda vücut sıcaklığı değerlerinde düşüş olduğunu tespit etmişlerdir. İnsan vücudunda 1s1 düzenleme mekanizmaları; radyasyon, konveksiyon kondüksiyon ve evaporasyon sonucu gerçekleşir. Vücutta 1sı üretiminde etkili faktörler incelendiğinde metabolik hız, kas kasılması, sıcak ortam, dehidrasyon ve egzersize bağlı olarak artış olduğu görülmektedir (Günay, Tamer ve Cicioğlu, 2010). Yapılan bu çalışmada, havuz uygulaması grubunda vücut sıcaklığı değerlerinde azalma olduğu görülmektedir. Havuz uygulamasında vücut sıcaklığındaki bu düşüşün nedeninin uygulama su içerisinde gerçekleştiği için kondüksiyona bağlı olduğu söylenebilir. Kara uygulaması grubunda ise artış olduğu görülmektedir. Kara uygulamasındaki bu artışın nedeni ise antrenmana bağlı olarak kasların yoğun olarak çalışması, çevresel faktörler, su uygulamasına göre daha sıcak ortamda egzersiz yapılması ve giysi kullanımı olduğu söylenebilir.

Yapılan bu çalışmada, her iki uygulamanın vücut ağırlığı değerleri incelendiğinde hem su uygulaması hem de kara uygulamasında vücut ağırlığında anlamlı düşüş olduğu gözlenmiştir (Tablo 4). Su içerisinde yapılan uygulamada vücut ağırlığında \%0,31 oranında düşüş olduğu, karada yapılan antrenmanlarda ise $\% 0,83$ düşüş olduğu tespit edilmiştir $(p<0,05)$ (Tablo 4$)$. Benzer şekilde Hazır ve diğerleri (2020) ile Yapıcı ve diğerleri (2017) yapmış oldukları çalışmada katılımcıların vücut ağırlıklarının sıvı takviyeli antrenman sonrasında yaklaşık 0.04 $\mathrm{kg}$, sıvı takviyesiz antrenman sonrasında yaklaşık $0.63 \mathrm{~kg}$ azaldığını tespit etmişlerdir. Aynı şekilde Dölek ve diğerleri (2014), yapmış oldukları çalışmada katılımcıların vücut ağırlığ değerlerini antrenman öncesi ve sonrasında incelemiş ve istatistiksel olarak anlamlı düşüş olduğunu tespit etmişlerdir. Katılımcıların vücut ağırlığındaki azalmada yapılan yoğun egzersiz terlemeye bağlı olarak hızlı kilo kaybına neden olmakta, bu da vücut sıvılarının eksilmesine neden olmaktadır (Pehlivan, 2005).

Çalışmamızda, katılımcıların toplam vücut sıvı yüzdesinde (hem su uygulaması hem de kara uygulamasında) istatistiksel olarak anlamlı düşüş olduğu tespit edilmiştir. Su uygulaması sonrasında düşüş \%2,73, kara antrenman uygulaması sonrası ise düşüş $\% 1,65$ 'tir $(\mathrm{p}<0,05)$ (Tablo 5). Benzer şekilde Yapıcı ve diğerlerinin (2017) yapmış oldukları çalışmada yüzücülere ait toplam vücut sıv1 yüzdesi, sıv1 takviyeli antrenman sonrasında düşüşün $\% 2,23$; sıv1 takviyesiz antrenmanda, antrenman sonrası toplam vücut sıvısındaki düşüşün \%1,54 olduğu belirlenmiştir. Sonuçlarda, karada olduğu gibi, su içi egzersizlerinin de vücutta sıvı kaybına yol açtığı görülmektedir. Aynı şekilde Dölek ve diğerleri (2014) yapmış oldukları çalışmada katılımcıların toplam vücut sıvı değerlerini antrenman öncesi ve sonrası incelemiş ve istatistiksel olarak anlamlı düşüş olduğunu tespit etmiştir. Yapılan çalışmalarda belirtildiği şekliyle vücut ağırlığının \%2-3'lük sıvı kaybı dayanıklılık, \%4'lük kaybı kuvvet, \%6'lık kaybı koordinasyon bozukluklularına neden olabilmektedir. Vücut ağırlığında \%10'luk sıvı kaybı ise sporcunun yaşamını tehdit eden sınırları aşmış olur (Güneş, 2005; Kanopka, 2005; Pehlivan, 2005).

Bu çalışmada, katılımcıların toplam kas oranı incelendiğinde hem su uygulaması hem de kara uygulamasında istatistiksel olarak anlamlı düşüş olduğunu tespit edilmiştir. Su uygulaması sonrasında düşüş \%2,25 kara antrenman uygulaması sonrası ise düşüş $\% 1,78$ 'tir $(p<0,05)$ (Tablo 6). Kas oranındaki düşüşün nedeni; katılımcıların uyguladığı antrenman ve terlemeye bağlı olarak olduğu düşünülmektedir. Kısa süre içerisinde gerçekleştirilen yoğun antrenmanlar 
vücut sıvılarının ve karbonhidrat depolarının hızla boşalmasına neden olmaktadır. Karbonhidrat depolarındaki hızlı tükenme glikojenezis sürecinin artmasına neden olmakta, buna bağlı olarak da kaslarda yıkım meydana gelmektedir. Bunun sonucunda da kas dokusunda azalma meydana gelmektedir. Buna ek olarak oluşan vücut sıvılarındaki azalma, kasların kesit alanın düşmesine neden olmaktadır (Kukidome ve diğerleri, 2008).

Yapılan bu çalışmada katılımcıların yağ oranları incelendiğinde hem karada hem de su uygulamasında artmış olduğu görülmektedir (Tablo 7). Benzer şekilde Dölek ve diğerleri (2014) ile Yapıcı ve diğerlerinin (2017) yapmış oldukları çalışmalarda yüzücülere ait toplam yağ yüzdesinde artış olduğunu tespit etmişlerdir. Vücut kompozisyonunda bir hafta içerisindeki değişimin \%70'i vücut sıvılarından, \%25'i yağlardan, \%5'i ise proteinlerden eksilmektedir. 2-3 hafta içerisinde gerçekleştirilen değişimin ise \%70'i yağlardan, \%20'si vücut sıvılarından \%10'u ise proteinlerden oluşmaktadır. Bu süre 4 haftaya çıktığında ise \%85'i yağlardan, \%15'i ise proteinlerden eksilmekte ve vücut sıvılarında ise her hangi bir azalma meydana gelmemektedir (Katch, McArdle ve Katch, 2011; Wilmore ve Costill, 2004). Yukarıdaki bilgiye dayanarak akut 2 saatlik antrenmanlarda vücut kompozisyonundaki değişimin büyük çoğunluğu vücut sıvılarından eksilmektedir. Yapılan bu çalışmada ve ilgili literatürde akut uygulamalarda yă̆ oranının artma sebebi, Tanita yă̆ analizörü ile yapılan ölçümlerde vücut sıvılarındaki ani azalmanın yağ oranını artmış olarak göstermesidir.

Sonuç olarak; yapılan bu çalışma sonucunda elde edilen veriler doğrultusunda kara ve su içerisinde yapılan antrenmanlarda vücut kompozisyonundaki değişiklikler büyük oranda benzerlik göstermektedir. Bu bakımından hem kara hem de su içerisinde yapılan antrenmanlarda sıvı alımına dikkat edilmesi önerilmektedir. Sporcuların bilimsel literatür eşliğinde antrenman öncesi, sırası ve sonrası su tüketimi ilkelerine uymaları tavsiye edilmektedir. 


\section{KAYNAKLAR}

Adams, J. D., Kavouras, S. A., Robillard, J. I., Bardis, C. N., Johnson, E. C., Ganio, M. S., \& White, M. A. (2016). Fluid balance of adolescent swimmers during training. The Journal of Strength \& Conditioning Research, 30(3), 621-625.

Armstrong, L.E. (2005). Hydration assessment techniques. Nutrition Reviews, 63(6), 40-54. https://doi.org/10.1111/j.1753-4887.2005.tb00153.x.

Arnaoutis, G., Kavouras, S. A., Angelopoulou, A., Skoulariki, C., Bismpikou, S., Mourtakos, S., \& Sidossis, L. S. (2015). Fluid balance during training in elite young athletes of different sports. Journal of strength and conditioning research/National Strength \& Conditioning Association, 29(12), 3447.

Baysal, A. ( 1997). Beslenme. 7. Baskı, Ankara: Hatipoğlu Yayınevi, 103-107.

Bompa, T.O. (2001). Antrenman kuramı ve yöntemi. Ankara: Bağırgan Yayımevi.

Çırak, O. ve Çakıroğlu Funda. P. (2017). Sporcularda sıvı dengesi ve performansa etkisi. Ankara Sağllk Bilimleri Dergisi, 6(1), 139-150. https://doi.org/10.1501/Asbd_0000000067.

Dölek, B.E., Yıldıran, İ. ve Koz, M. (2014). Yüzmenin neden olduğu vücut sıvı dengesindeki değişimlerin yüzme performansına etkisi. Spormetre Beden Eğitimi ve Spor Bilimleri Dergisi, 12(2), 89-104. https://doi.org/10.1501/Sporm_0000000257.

Ersoy, N., Er, D. ve Özgürtaş, T. (2013). Adolesan yüzücülerin antrenman sırasında sıvı kayıplarının değerlendirilmesi. Beslenme ve Diyet Dergisi, 41(3), 221-226.

Gökdemir, K. (2000). Güreş antrenmanının bilimsel temelleri. 1.Baskı, Ankara: Poyraz Ofset, 196-199.

Günay, M., Tamer, K. ve Cicioğlu, İ. (2010). Spor fizyolojisi ve performans ölçümü. 2. Baskı Ankara: Özbaran Ofset Matbaacilik.

Güneş, Z. (2005). Spor ve beslenme. 4.Baskı, Ankara: Nobel Yayım ve Dağıtım.

Hazır, T., Köse, M. G., Esatbeyoğlu, F., Ekinci, Y. E. ve İşler, A. K. (2020).Yüksek şiddetli egzersizin bioelektrik impedans yöntemi ile ölçülen vücut kompozisyonu üzerine etkisi. Spor Hekimliği Dergisi, 55(2), 102111. https://doi.org/ 10.5152/tjsm.2020.166.

Hoffman, J. (2002). Physiological aspects of sports training and performance. $1^{\text {th }}$ Ed. USA Champaign: Human Kinetics Publishers.

Katch, V.L., McArdle, V.D. \& Katch, F.I. (2011). Essentials of exercise physiology. $4^{\text {th }}$. Ed., Philadelpia: Lippincott Williams \& Wilkins.

Konopka, P. (2000). Spor beslenmesi. (H. Harputluoğlu, Çev.) Ankara: Bağırgan Yayımevi, 114-121.

Kukidome, T., Shirai, K., Kubo „J., Matsushima, Y., Yanagisawa, O., Homma, T. et al. (2008). MRI evaluation of body composition changes in wrestlers undergoing rapid weight loss. Br J Sports Med, 42, 814-818. http://dx.doi.org/10.1136/bjsm.2007.044081.

Macaluso, F., Di Felice, V., Boscaino, G., Bonsignore, G., Stampone, T., Farina, F., \& Morici, G. (2011). Effects of three different water temperatures on dehydration in competitive swimmers. Science \& Sports, 26(5), 265-271.

Masento, N. A., Golightly, M., Field, D. T., Butler, L. T., \& van Reekum, C. M. (2014). Effects of hydration status on cognitive performance and mood. British Journal of Nutrition, 111(10), 1841-1852.

Pehlivan, A. (2005). Sporda beslenme. İstanbul: Yaylacık Matbaası.

Sevim, Y. (2007). Antrenman bilgisi. 7. Baskı, Ankara: Nobel Yayın Dağıtım, 308-309.

Shirreffs, S. M. (2009). Hydration in sport and exercise: water, sports drinks and other drinks. Nutrition bulletin, 34(4), 374-379. 
Singh, R. (2003). Fluid balance and exercise performance. Malaysian journal of nutrition, 9(1), 53-74.

Wilmore, J.H. \& Costill, D.L. (2004). Physiology of sport and exercise. 3rd Edition, USA: Human Kinetics.

Yapıcı, A., Kavruk, H. ve Çelik, E. (2017). Yüzücülerde eşik dayanıklılık antrenmanı (end-2) sonucunda oluşan dehidrasyonun performans üzerine etkileri ve vücut hidrasyon düzeyinin incelenmesi. Uluslararası Kültürel ve Sosyal Araştırmalar Dergisi (UKSAD), 3 (Special Issue 2), 372-381.

Bu eser Creative Commons Atıf-GayriTicari 4.0 Uluslararası Lisansı ile lisanslanmıştır. 